\title{
SEQÜÊNCIAS DIDÁTICAS PARA DESENVOLVIMENTO DA HABILIDADE DE LEITURA EM LÍNGUA INGLESA: ELABORAÇÃO E APLICAÇÃO
}

Paula Tatianne Carréra SZUNDY

Universidade Federal do Acre

\begin{abstract}
Resumo: Esse artigo tem como objetivo descrever o projeto Sequiências didáticas para a construção da haMidade de leitura em lingua inglesa: elaboração e aplicaçãoYcpíe está sendo desenvolvido nas minhas aulas de Prática de Ensino da Língua Inglesa na Universidade Federal do Acre com o apoio do Programa de Consolidação de Licenciaturas Prodocência 2006 (MEC/SESU/DEPEM). Com base na concepção de que as aulas de Prática de Ensino no curso de graduação em Letras devem formar o professor-pesquisador envolvido em um processo contínuo de reflexão sobre suas próprias ações e engajado na busca de transformações para práticas pedagógicas vigentes, o projeto em questão tem como foco o desenvolvimento de seqüências didáticas para construção da habilidade de leitura em língua inglesa e a posterior aplicação dessas seqüências em um curso de extensão oferecido para alunos do ensino médio. As seqüências didáticas foram elaboradas pelos graduandos do $8^{\circ}$ período sob a minha orientação a partir das diretrizes curriculares postuladas pelos PCNs de língua estrangeira e língua materna e em teorias sobre gêneros discursivos e ensino. Após a contextualização do projeto e a breve descrição das seqüências didáticas, apresento uma discussão baseada nos recortes dos planos de curso elaborados pelos alunos-professores a fim de suscitar a reflexão sobre o processo de formação que pode ser depreendido da análise desses planos de curso.
\end{abstract}

Palavras-chave: gênero, seqüência didática, leitura, reflexão

Abstract: This paper aims at describing the project Didactic Sequences
for developing the reading skill in the EFL classroom: elaboration and
application that is being developed in an EFL Methodology course taught
by me at Universidade Federal do Acre with the support of the
"Programa de Consolidação de Licenciaturas Prodocência 2006" 
(MEC/SESU/DEPEM). Based on the conception that EFL Methodology courses in Letras graduation are supposed to prepare the teacher-researcher engaged in a continuous reflective process about his/her own actions and in the search of transformation for traditional pedagogical practices, the project hás as its focus the development of didactic sequences to construct the reading comprehension skill in English as a foreign language and the posterior application of these sequences in a reading course given to high school students. The didactic sequences were elaborated by $8^{\text {th }}$ period graduate students under my supervision having as their theoretical framework the proposals postulated by the official curricular parameters ( $\mathrm{PCNs}$ ) of foreign language and mother tongue as well as theories concerned with the relation between discourse genres and teaching. After contextualizing the project and briefly describe the didactic sequences developed, I present an analysis of excerpts taken from the course plan prepared by the graduate students só as to raise a reflection about the teacher education process that can be visualized in these course plans.

Key words: genre, didactic sequence, reading, reflection

Resumen: El presente artículo tiene como objetivo describir el proyecto Secuencias didácticas para Ia construcción de Ia babilidad lectora en inglês: elaboración y aplicación, que se desarrolla en mis clases de Practica de Ensenaza de Inglês en Ia Universidad Federal dei Acre, con el soporte dei "Programa de Consolidação de Licenciaturas Prodocência 2006" (MEC/SESU/ DEPEM). Con bases en el concepto de que Ias clases de Práctica de Ensenanza en el curso de Letras deben de formar a un profesorinvestigador involucrado en un continuado proceso de reflexión sobre sus propias acciones y enganchado en Ia búsqueda de una transformación para Ias prácticas pedagógicas actuales, dicho proyecto posee como objetivo el desarrollo de secuencias didácticas para Ia construcción de Ias habilidades lectoras en lengua inglesa y su aplicación en un curso de extensión ofrecido para alumnos dei Bachiller (Ensino Médio). Lãs secuencias fueron elaboradas por los alumnos dei curso de Letras dei $8^{\circ}$ semestre bajo mi orientación y a partir de los princípios curriculares propuestos por los PCNs de lengua extranjera y lengua materna, adernas de basarse aún en Ias teorias sobre los gêneros discursivos y su ensenanza. Después de presentar el contexto dei proyecto y una resumida descripción de Ias secuencias didácticas, 
presente una discusión basada en los extractos sacados de los planes de curso producidos por los alumnos-profesores, con el propósito de fomentar Ia reflexión sobre su proceso de formación a través dei análisis de dichos planes.

Palabras clave: gênero, secuencia didáctica, lectura, reflexión.

\section{Introdução}

A busca de caminhos que desencadeiem um processo de formação de professores crítico e emancipatório tem ocupado lugar de destaque nas discussões e pesquisas desenvolvidas nas áreas de Educação e Linguística Aplicada da última década. Tal busca está estreitamente ligada à crescente mudança de paradigma em relação ao papel do professor, que propõe que, além de dominar o conhecimento técnico e pedagógico da sua área de atuação específica, este deve se tornar um pesquisador da sua própria prática. Para se tornar professorpesquisador é fundamental que o educador desenvolva a capacidade de transpor os conhecimentos teórico-metodológicos construídos nos cursos ou programas de formação de professores em serviço ou préserviço para situações concretas de ensino-aprendizagem de forma a se engajar e engajar o(s) outro(s) (colega(s), aluno(s), coordenador(es), etc.) em um processo de reflexão contínuo que leve à construção colaborativa do conhecimento e à consequente transformação de práticas pedagógicas vigentes.

Nos cursos de licenciaturas, as Práticas de Ensino podem se tornar espaços privilegiados para construção do conhecimento e reflexão crítica sobre a futura prática pedagógica. Para que isso ocorra, parece-me fundamental que essas Práticas engajem o futuro professor em projetos pedagógicos que o levem a vivenciar a sala de aula (muito além da mera observação de aulas), criando espaços para que os conhecimentos teóricos, técnicos e metodológicos construídos no decorrer do curso sejam transpostos para situações concretas de ensinoaprendizagem e tornados alvos de avaliação e reflexão contínua nas aulas de Prática de Ensino.

É justamente a concepção de que as aulas de Prática de Ensino no curso de graduação em Letras devem formar o professorpesquisador envolvido em um processo contínuo de reflexão crítica sobre suas próprias ações e engajado na busca de transformações para 
práticas pedagógicas vigentes que orientou a elaboração do projeto Sequiências Didáticas para Desenvolvimento da Habilidade de Leitura em Lingua Inglesa: Elaboração e Aplicação, que buscou nos Parâmetros Curriculares Nacionais (doravante PCNs) de Língua Estrangeira (doravante LE) e Língua Materna (doravante LM) (BRASIL, 1998a) e nas teorias sobre gêneros do discurso e ensino (BAKHTIN, 1953; DOLZ; SCHNEUWLY, 2004; ROJO, 2001, 2005) subsídios teóricos e metodológicos para implementação de uma proposta pedagógica para a construção da habilidade de leitura em língua inglesa no ensino médio.

Embora projetos baseados na concepção de gêneros do discurso venham sendo desenvolvidos por vários pesquisadores brasileiros em contextos de ensino-aprendizagem de LE variados (CRISTOVÃO, 2002, 2005; PINTO, 2002; SZUNDY, 2004; RAMOS, 2005; ROJO, 2001, entre outros) e em programas de formação continuada de professores de LE (CELANI, 2002), as questões teóricas relacionadas às teorias de gêneros do discurso assim como suas possíveis transposições para situações concretas de ensino-aprendizagem não têm tido o destaque necessário na formação pré-serviço do graduando de Letras, habilitação em língua inglesa, na Universidade Federal do Acre.

Ao invés de se constituir em um espaço privilegiado para a vivência da prática pedagógica, as aulas de Prática de Ensino vêm sendo conduzidas a partir de discussões teóricas e metodológicas diversas, da mera observação de aulas no ensino fundamental e médio e da escritura de relatório final meramente descritivo e não críticoreflexivo sobre as práticas observadas. Apesar de a observação de práticas pedagógicas vigentes ser importante para formação do futuro professor de LE, acredito que essa observação deve ser conduzida de maneira crítica e orientada por construtos teóricos diversos de forma a permitir que a investigação pedagógica e o estágio supervisionado criem espaços para a colaboração, intervenção e possíveis transformações das ações em sala de aula.

Diante desse fato, o projeto especificado acima nasceu da necessidade premente de fazer da Prática de Ensino no Curso de Letras, habilitação em língua inglesa, um espaço para reflexão crítica sobre o processo de ensino-aprendizagem de LE em que a relação teoria e prática seja construída por meio de projetos de pesquisa que levem o aluno a vivenciar, interferir e buscar transformações para o processo de construção de conhecimento da LE. 
Nesse sentido, o projeto está comprometido com a formação do professor-pesquisador capaz de refletir criticamente sobre as suas práticas e as práticas de outrem, além de intervir e buscar transformações de forma informada, ou seja, teoricamente fundamentada, no espaço onde atua.

\section{Gêneros discursivos e ensino de línguas}

O projeto Sequiências didáticas para a construção da habilidade de leitura: elaboração e aplicação, conforme indicado no próprio título, é composto por duas etapas centrais, sendo a primeira referente à elaboração das seqüências didáticas e a segunda destinada à aplicação dessas seqüências em um curso de extensão destinado a alunos do ensino médio.

Durante a primeira etapa, textos teóricos diversos foram lidos com o intuito de discutir concepções acerca do processo de leitura em LE e alguns construtos centrais relacionados à noção de gêneros do discurso e possibilidade de transposição de gêneros para sala de aula de LE para se construir a habilidade de leitura.

As discussões sobre concepções de leitura, basearam-se fundamentalmente nas propostas curriculares dos PCNs de LE e LM (BRASIL, 1998a, 1998b) para o ensino fundamental e a noção de gênero foi construída a partir da leitura do texto Os gêneros do discurso (BAKHTIN, 1953) e de outros textos que tratam da transposição da teoria de gêneros para situações de ensino-aprendizagem de línguas (CRISTOVÃO, 2002; DOLZ; SCHNEUWLY, 2004; MARCUSCHI, 2005; ROJO, 2001).

São, portanto, as concepções teóricas que embasam esse projeto que discuto brevemente a seguir.

Fundamentados em uma visão sociointeracional da linguagem, os PCNs de LE propõem que a aprendizagem "centre-se no engajamento discursivo do aprendiv, ou seja, em sua capacidade de se engajar e engajar outros no discurso de modo a poder agir no mundo social" (Brasil, 1998a), p. 15). Dada a estrutura da escola, o tempo destinado à aprendizagem de LE e as necessidades futuras do aluno em cursos de graduação e pós-graduação, os PCNs propõem que se enfoque a construção da habilidade de leitura, buscando nessa construção o engajamento discursivo e negociação de significados entre os participantes do 
discurso, levando-se em conta os aspectos institucionais, sociais, culturais e históricos essenciais para que a construção conjunta de significados ocorra.

Segundo os PCNs de LE (BRASIL, 1998a), as pessoas mobilizam três tipos de conhecimento para construção de significados de natureza sociointeracional, sendo eles conhecimento de mundo, conhecimento sistémico e conhecimento da organização textual.

O conhecimento de mundo está relacionado ao préconhecimento que todos nós temos sobre as coisas do mundo e pode ser relacionado com o conhecimento cotidiano proposto por Vygotsky (1934). Já o conhecimento sistêmico permite que façamos escolhas gramaticalmente adequadas quando produzimos nossos enunciados. O conhecimento da organização textual, por sua vez, engloba o conhecimento das rotinas interacionais de textos orais e escritos diversos.

Diferentemente do conhecimento de mundo, que é pré-existente, o conhecimento sistêmico e da organização textual são construídos na escola em constante e ininterrupto diálogo com o conhecimento prévio constituído na interação com o(s) outro(s) nas diversas instituições no meio social, estando, portanto, na esfera do que Vygotsky (1934) classifica como conhecimento científico.

Embora não elaborada a partir da concepção de gêneros do discurso, a proposta pedagógica fundamentada em uma visão sociointeracional da linguagem defendida pelos PCNs de LE apresenta pontos de tangência com os estudos de Schneuwly \& Dolz (2004), que propõem que os gêneros do discurso sejam utilizados como instrumentos de ensino-aprendizagem que levem ao desenvolvimento de capacidades de linguagem específicas. Buscando uma aplicação didática da concepção bakhtiniana de gêneros do discurso, Schneuwly \& Dolz (2004) propõem um currículo flexível para o ensino de francês como LM, delineado a partir de agrupamentos de gêneros. Esse currículo prevê um enfoque em espiral para o processo de ensinoaprendizagem, sugerindo que os mesmos gêneros podem ser retomados em todas as séries do ensino básico com objetivos semelhantes, mas em níveis de complexidade cada vez maiores ao longo da escolaridade.

Da mesma forma que o domínio de rotinas interacionais está envolvido no conhecimento da organização textual destacado nos PCNs, a mestria de um gênero, como sublinham Dolz \& Schneuwly 
(2004), requer a mestria de situações de comunicação específicas. Fundamentados em uma perspectiva bakhtiniana, os autores definem três dimensões essenciais do gênero que devem orientar o processo de ensino-aprendizagem de LM a partir de gêneros do discurso:

1. Os conteúdos que são (que se tornam dizíveis) através dele;

2. A estrutura (comunicativa) particular dos textos pertencentes ao gênero;

3. As configurações específicas das unidades de linguagem, que são sobretudo traços da posição enunciativa do enunciador, e os conjuntos particulares de seqüências textuais e de tipos discursivos que formam sua estrutura (DOLZ; SCHNEUWLY, 2004, p. 52).

À semelhança da proposta de Dolz \& Schneuwly para o ensino de francês como LM, os Parâmetros Curriculares Nacionais de Língua Portuguesa para o Ensino Fundamental (BRASIL, 1998b) também sugerem diretrizes para elaboração de currículos com base em uma reflexão didática sobre a concepção bakhtiniana de gêneros do discurso. No entanto, conforme aponta Rojo (2001), diferentemente do agrupamento baseado em capacidades de linguagem realizado pelos pesquisadores de Genebra, nos PCNs os gêneros estão agrupados em função da sua circulação social (gêneros literários, de imprensa, publicitários e de divulgação científica), "levando-se em conta os usos sociais mais frequentes (leitura/escuta; produção de textos orais e escritos) dos textos, no que se refere aos gêneros selecionados" (ROJO, 2001, p. 35).

Szundy (2004) destaca a contribuição dos trabalhos desenvolvidos a partir da teoria de gêneros do discurso para o repensar sobre o processo de construção do conhecimento e constituição da linguagem e propõe a aplicação da teoria da enunciação bakhtiniana tanto na análise da interação quanto no desenvolvimento de uma proposta didática baseada na concepção de gêneros discursivos na sala de aula de LE.

A esse respeito, Rojo (2005) sublinha a grande atenção que tem sido dada no campo da Linguística Aplicada, especialmente na esfera de ensino-aprendizagem de línguas, à teoria de gêneros a partir de meados da década de noventa. Em um levantamento realizado no Programa de Linguística Aplicada ao Ensino de Línguas (LAEL) da 
PUC-SP, Rojo encontrou sessenta e três trabalhos inseridos no campo linguagem na educação cujo referencial se fundamentava em teorias de gêneros aplicadas ao ensino-aprendizagem de línguas (materna ou estrangeira), práticas de letramento, formação de professores e elaboração de materiais didáticos.

Essa transposição significativa das teorias de gênero para as situações de ensino-aprendizagem de línguas deve-se, de acordo com Rojo (2005, p. 184):

[...] aos novos referenciais nacionais de ensino de linguas (PCNs de lingua portuguesa, de linguas estrangeiras) que fazem indicaşão explícita dos gêneros como objetos de ensino ou destacam a importância de considerar as características dos gêneros, na leitura e na producão dos textos.

As pesquisas realizadas por Pinto (2002) e Cristovão (2001) constituem exemplos dessa transposição de teorias de gêneros para situações de ensino-aprendizagem de língua inglesa.

O estudo realizado por Pinto (2002), que integra o projeto Gêneros Textuais: implicações na compreensão/produção do aluno universitário desenvolvido no Departamento de Letras da UFPE, buscou, em sua fase inicial, levantar as dificuldades e/ou facilidades apresentadas pelos alunos na produção de gêneros textuais que envolvem a capacidade de relatar, expor ou narrar fatos na LE como, por exemplo, cartas formais e informais, slogans e cartões postais.

Cristovão (2001) trata da transposição da teoria de gêneros para ensino de leitura em LE. A partir da análise de seqüências didáticas especialmente elaboradas para o Projeto de Correção de Fluxo para alunos repetentes e multirrepetentes de $5^{\mathrm{a}}$, $6^{\mathrm{a}}$ e $7^{\mathrm{a}}$ séries do estado do Paraná, a pesquisa de Cristóvão defende o uso de modelos didáticos de gêneros para elaboração e avaliação de materiais didáticos voltados para o ensino de leitura em LE.

O projeto de formação pré-serviço aqui discutido compartilha com esses pesquisadores a visão de que o trabalho com gêneros do discurso no processo de ensino-aprendizagem de línguas pode levar a práticas de produção e compreensão de textos diferenciadas que despertem "a réplica ativa e a flexibilidade dos sentidos na polissemia dos signos, [...] (ao invés) de ensinar o aluno a reconhecer, localizar e repetir os significados dos textos" (ROJO, 2005, p. 207). 


\section{Objetivos, contexto e estratégias de execução do Projeto}

O Projeto Sequiencias didáticas para o desenvolvimento da habilidade de leitura em língua inglesa: elaboração e aplicação, buscando uma formação diferenciada nas aulas de Prática de Ensino da UFAC, pretende fazer com que os graduandos do curso de Letras, habilitação em língua inglesa:

- desenvolvam seqüências didáticas a partir das concepções postuladas pelos PCNs e pelas teorias de gêneros para o ensino da leitura em língua inglesa;

- apliquem essas seqüências didáticas em um curso de extensão voltado para alunos do ensino médio;

- avaliem continuamente essa aplicação nas aulas de Prática de Ensino;

- relatem os resultados da experiência em relatórios, artigos científicos, comunicações em painéis que podem ser publicados em periódicos e/ou apresentados em eventos da área.

A parte do projeto referente ao curso de extensão para os alunos do ensino médio foi realizada no Colégio de Aplicação da Universidade Federal do Acre (CAP-UFAC) entre fevereiro e março de 2007.

O CAP-UFAC, escola de ensino fundamental e médio criada em 1981, representa um espaço privilegiado para aplicação de projetos pedagógicos desenvolvidos pelos vários cursos de licenciatura da UFAC e a sua existência como espaço voltado para essa aplicação favorece a realização de projetos como esse, que, além de contribuir para formação do graduando em Letras/Inglês, pretende interferir no processo de ensino-aprendizagem nessa instituição de ensino, engajando coordenadores, professores, graduandos e alunos na construção colaborativa do conhecimento sobre a prática pedagógica da LE.

O projeto foi desenvolvido no decorrer do segundo semestre académico de 2006 da UFAC, que se realizou de outubro de 2006 a março de 2007. As ações, membros envolvidos e seus respectivos papéis e períodos de realização estão detalhados no quadro a seguir. 


\begin{tabular}{|c|c|c|c|}
\hline ETAPAS & AÇÕES & $\begin{array}{c}\text { MEMBROS } \\
\text { ENVOLVIDOS E } \\
\text { PAPÉIS }\end{array}$ & PERÍODO \\
\hline $\begin{array}{l}\text { 1. Leitura dos } \\
\text { PCNs e de } \\
\text { textos teóricos } \\
\text { diversos sobre } \\
\text { teorias de } \\
\text { géneros e } \\
\text { ensino }\end{array}$ & $\begin{array}{l}\text { discussão em sala de } \\
\text { aula; } \\
\text { fichamento, resenhas } \\
\text { e seminários; } \\
\text { reflexão sobre } \\
\text { implicações para } \\
\text { prática pedagógica. }\end{array}$ & $\begin{array}{l}\text { graduandos do } 2^{\circ} \mathrm{e} \\
\text { do } 8^{\circ} \text { período de } \\
\text { Letras/Inglês, } \\
\text { cursando disciplinas } \\
\text { relacionadas à Prática } \\
\text { de Ensino da Língua } \\
\text { Inglesa. }\end{array}$ & $\begin{array}{l}\text { durante } \\
\text { todoo } \\
\text { período de } \\
\text { realização do } \\
\text { projeto. }\end{array}$ \\
\hline $\begin{array}{l}\text { 2. Desenvol- } \\
\text { vimento das } \\
\text { seqüências } \\
\text { didáticas }\end{array}$ & $\begin{array}{l}\text { divisão em grupos } \\
\text { de trabalho de acordo } \\
\text { com as três séries do } \\
\text { ensino médio. }\end{array}$ & $\begin{array}{l}\text { graduandos do } 8^{\circ} \\
\text { período - elaboração, } \\
\text { avaliação e análise das } \\
\text { seqüências. } \\
\text { professora - } \\
\text { supervisão e mediação } \\
\text { entre teorias discutidas } \\
\text { e atividades propostas } \\
\text { na seqüência. } \\
\text { graduandos do } 2^{\circ} \\
\text { período - avaliação } \\
\text { das seqüências com } \\
\text { base em pressupostos } \\
\text { teóricos discutidos. }\end{array}$ & $\begin{array}{l}\text { - janeiro de } \\
2007\end{array}$ \\
\hline $\begin{array}{l}\text { 3. Aplicação } \\
\text { das } \\
\text { sequêencias } \\
\text { didáticas no } \\
\text { Colégio de } \\
\text { Aplicação da } \\
\text { UFAC }\end{array}$ & $\begin{array}{l}\text { formação de três } \\
\text { grupos com um total } \\
\text { de aproximadamente } \\
80 \text { alunos formados } \\
\text { por alunos do } 1^{\circ}, 2^{\circ} \mathrm{e} \\
3^{\circ} \text { ano do ensino } \\
\text { médio e professores do } \\
\text { CAP interessados em } \\
\text { participar do projeto. } \\
\text { aplicação das } \\
\text { seqüências didáticas } \\
\text { de acordo com os } \\
\text { grupos de trabalho } \\
\text { mencionados na } \\
\text { segunda etapa. }\end{array}$ & $\begin{array}{l}\text { graduandos do } 8^{\circ} \\
\text { período - aplicação } \\
\text { das sequêências } \\
\text { didáticas e avaliação } \\
\text { das ações em sala de } \\
\text { aula. } \\
\text { graduandos do } 2^{\circ} \\
\text { período - observação e } \\
\text { análise da prática dos } \\
\text { colegas do } 8^{\circ} \text { período. } \\
\text { professora - } \\
\text { supervisão e avaliação } \\
\text { contínua da } \\
\text { implementação do } \\
\text { projeto } \\
\text { alunos - avaliação } \\
\text { do próprio processo de } \\
\text { ensino-aprendizagem e } \\
\text { do aluno-professor no } \\
\text { processo de } \\
\text { implementação da } \\
\text { proposta pedagógica } \\
\text { por meio de } \\
\text { questionários. } \\
\text { coordenador } \\
\text { pedagógico e } \\
\text { professores de Língua } \\
\text { Inglesa do Colégio de } \\
\text { Aplicação - } \\
\text { observação e avaliação } \\
\text { dos impactos do } \\
\text { projeto. }\end{array}$ & $\begin{array}{l}\text { fevereiro e } \\
\text { março de } \\
2007 \text {; } \\
\text { dois } \\
\text { encontros } \\
\text { semanais de } \\
\text { duas horas } \\
\text { cada um, } \\
\text { totalizando } \\
\text { aproximadam } \\
\text { ente 20 } \\
\text { horas/aula. }\end{array}$ \\
\hline
\end{tabular}




\begin{tabular}{|c|c|c|c|}
\hline $\begin{array}{l}\text { 4. Avaliação } \\
\text { contínua da } \\
\text { aplicação das } \\
\text { seqüências } \\
\text { didâticas }\end{array}$ & $\begin{array}{l}\text { - avaliação da própria } \\
\text { prática e da prática dos } \\
\text { colegas com base nos } \\
\text { objetivos estabelecidos } \\
\text { nas sequêencias } \\
\text { didâticas, nos } \\
\text { objetivos alcançados } \\
\text { na aplicação das } \\
\text { seqüências e nos } \\
\text { pressupostos teóricos } \\
\text { discutidos e analisados } \\
\text { nas aulas de Prática de } \\
\text { Ensino. }\end{array}$ & $\begin{array}{l}\text { graduandos do } 8^{\circ} \\
\text { período - auto- } \\
\text { avaliação da própria } \\
\text { prática e avaliação da } \\
\text { prática de outrem. } \\
\text { graduandos do } 2^{\circ} \\
\text { período - avaliação da } \\
\text { prática dos colegas. } \\
\text { professora - } \\
\text { mediação de } \\
\text { discussões e } \\
\text { proposições de } \\
\text { atividades que levem } \\
\text { os graduandos a } \\
\text { refletirem sobre a } \\
\text { experiência } \\
\text { pedagógica observada. }\end{array}$ & $\begin{array}{l}\text { fevereiro e } \\
\text { março de } \\
2007\end{array}$ \\
\hline $\begin{array}{l}\text { 5. Elabora- } \\
\text { ção de } \\
\text { relatórios, artigos } \\
\text { científicos, painéis, } \\
\text { comunicações, etc. }\end{array}$ & $\begin{array}{l}\text { divulgação da } \\
\text { experiência docente } \\
\text { em eventos e periódicos da } \\
\text { área. }\end{array}$ & $\begin{array}{l}\text { graduandos do } 8^{\circ} \text { e } \\
2^{\circ} \text { períodos - escritura } \\
\text { de artigos, relatórios, } \\
\text { apresentação de painéis ou } \\
\text { comunicações em eventos } \\
\text { da área. } \\
\text { professora - relatório } \\
\text { final das atividades } \\
\text { desenvolvidas e resultados } \\
\text { alcançados; escritura de } \\
\text { artigo e/ou capítulos de } \\
\text { livro analisando as várias } \\
\text { etapas e atividades do } \\
\text { projeto; apresentação dos } \\
\text { resultados em eventos. }\end{array}$ & $\begin{array}{l}\text { a partir de } \\
\text { março de } \\
20071\end{array}$ \\
\hline
\end{tabular}

\section{Seqüências didáticas elaboradas e análise dos planos de curso}

Conforme especificado no quadro acima, as seqüências didáticas foram elaboradas pelos alunos do $8^{\circ}$ período de Letras, habilitação em Língua Inglesa da UFAC sob supervisão da professora de Prática de Ensino da Língua Inglesa no decorrer do mês de janeiro de 2007.

Para descrição das seqüências didáticas e análise dos planos de curso, privilegio um método de análise que parte da situação social mais ampla, para o gênero e, por fim, para elementos da materialidade linguística que ilustrem a interpretação proposta. A meu ver, esse método de análise da língua, proposto por Bakhtin/Voloshinov (1929), é coerente com a tradição de pesquisa sócio-histórica em que me

\footnotetext{
${ }^{1}$ As atividades de divulgação dos resultados ocorrerão após a implementação do projeto e os dados coletados (seqüências didâticas, questionários, diários reflexivos, entre outros) poderão ser utilizados para publicações, pesquisa e programas de formação de professores futuros.
} 
considero inserida na medida em que postula a importância de elementos não verbais relacionados tanto à situação social mais ampla quanto à situação concreta de enunciação para compreensão do enunciado analisado em sua materialidade linguística.

Como professora adjunta recém integrada ao Departamento de Letras, área de Língua Inglesa, da Universidade Federal do Acre, venho tentando desde o início do meu contrato, em dezembro de 2005, assumir as disciplinas de Prática de Ensino. Isso se concretizou no primeiro semestre de 2006 com a implantação da nova grade curricular do Curso de Letras, que prevê quatrocentas horas da carga horária total do curso dedicadas à Prática de Ensino e Estágio Supervisionado.

Somando-se a esse fato, a aprovação do projeto proposto para o Programa de Consolidação de Licenciaturas Prodocência 2006 (MEC/SESu/DEPEM), que prevê, conforme já mencionado, um trabalho conjunto entre os alunos do $2^{\circ}$ e $8^{\circ}$ períodos, possibilitou que o estágio dos graduandos do último período de Letras/Inglês também ficasse sob minha supervisão no $2^{\circ}$ semestre de 2006.

A minha trajetória de seis anos no Programa de Linguística Aplicada e Estudos da Linguagem da PUC-SP e o engajamento em várias atividades académicas nessa e em outras instituições de ensino superior levaram à constituição de uma visão específica sobre o processo de ensino-aprendizagem, de constituição da linguagem e de formação de educadores. É essa visão, fundamentada por ideologias historicamente cristalizadas diversas (BAKHTIN/VOLOSHINOV, 1929), que orienta o projeto aqui descrito.

Como o estágio na disciplina de Prática de Ensino da Língua Inglesa baseava-se até então na observação de aulas de outros professores no ensino fundamental e médio e o máximo de experiência concreta em sala de aula que os alunos vivenciavam era dar aulas para seus próprios colegas de turma (experiência conhecida como microteaching), a mudança de paradigma imposta não foi destituída de conflitos e dificuldades.

O pouco tempo destinado à construção e discussão dos pressupostos teóricos que embasam o projeto representou uma das principais dificuldades encontradas. Como os alunos-professores não tinham familiaridade com os conceitos dos PCNs e com teorias de gêneros, os construtos teóricos básicos tiveram que ser construídos no 
decorrer das cento e vinte horas da disciplina, concomitantemente com o estágio no ensino fundamental e com a preparação das seqüências didáticas para o curso de extensão no ensino médio, o que implicou uma sobrecarga de trabalho e leituras para os alunos do $8^{\circ}$ período.

Somando-se a essa dificuldade, os conflitos foram de natureza teórico-ideológica. Em uma experiência anterior, no ensino fundamental, embora a prática tenha sido orientada a partir das diretrizes curriculares dos PCNs de LE (BRASIL, 1998a), algumas das práticas de ensino observadas constituíram-se no trabalho descontextualizado com o conhecimento sistémico, a gramática pela gramática, ou no uso do texto como pretexto para se trabalhar o conhecimento sistémico e lexical sem se levar em conta aspectos referentes à organização textual, ou seja, às características do gênero.

Essas práticas foram alvo de reflexão crítica e teoricamente fundamentada nas aulas de Prática de Ensino e contribuíram, de certa forma, para moldar a prática com as seqüências didáticas no ensino médio. $\mathrm{O}$ marcador de certa forma é utilizado propositalmente para relativizar a influência da prática anteriormente vivenciada no ensino fundamental, visto que, ao contrário dessa primeira experiência, no projeto com as seqüências didáticas não foi dada aos alunos-professores outra possibilidade senão a de ascender aos pressupostos teóricometodológicos do modelo didático proposto.

Assim, após a leitura de textos diversos e a discussão dos pressupostos teórico-metodológicos defendidos nesses textos, deu-se a preparação das seqüências didáticas pelos graduandos do $8^{\circ}$ período. Enquanto as discussões teóricas baseadas nas leituras sugeridas reuniram os alunos do $2^{\circ}$ e $8^{\circ}$ períodos, a etapa de preparação das seqüências didáticas envolveu apenas os alunos do $8^{\circ}$ período, que se subdividiram em pares ou em grupos de três alunos para seleção do gênero e elaboração do material.

A elaboração das seqüências didáticas envolveu as seguintes etapas:

- análise da seqüência didática desenvolvida a partir do gênero quarta capa de livro, que integra o material do Projeto de Correção de Fluxo da Secretaria de Estado da Educação do Paraná e é analisada por Cristovão (2002) no artigo O gênero quarta capa no ensino de inglês, lido e discutido em sala de aula; - seleção pelos alunos dos gêneros fábula, biografia e notícia para elaboração das seqüências didáticas para $01^{\circ}, 2^{\circ}$ e $3^{\circ}$ 
anos do ensino médio respectivamente;

- descrição dos gêneros fábulas, biografia e notícia e elaboração do plano de curso de cada seqüência didática;

- elaboração das atividades que integram as seqüências didáticas;

- apresentação e análise das seqüências didáticas em conjunto com os alunos do $2^{\circ}$ período.

Nas instruções dadas para elaboração do plano de curso de cada seqüência didática, delimitou-se que os alunos-professores deveriam considerar os seguintes aspectos: justificativa para escolha do gênero; objetivos (geral e específicos); desenvolvimento metodológico da seqüência didática e avaliação.

As justificativas encontradas no plano de curso das seqüências sobre biografias e notícias revelam a preocupação de tornar acessível a leitura em LE por meio do trabalho com esses dois gêneros.

Recorte 1 - Justificativa para escolha do gênero biografia

Uma vez que homem e história estão relacionados. acreditamos que ao utilizarmos a biografia sistematicamente, como um instrumento educacional, podemos incitar nos alunos a curiosidade quando se relata acontecimentos de uma pessoa famosa em que todos possam comentar sobre ela e acrescentar fatos relevantes, uma vez que, quando se trata de histórias sobre pessoas, histórias reais, elas se tornam ainda mais acessíveis, desenvolvendo no leitor a busca de informações e o prazer nessas leituras.

Recorte 2 - Justificativa para escolha do gênero notícia

Considerando o nível de escolaridade $\left(3^{\circ}\right.$ ano do Ensino Médio e Professores de Educação Básica) dos participantes do Curso Seqüências didáticas para a construção da habilidade de leitura em língua inglesa: elaboração e aplicação, o gênero Notícia foi escolhido por sua acessibilidade (aqui destacamos o fator Internet) e tendo como base a possível necessidade dos alunos em adquirir conhecimento de fatos em Língua Inglesa. Ressaltando ainda que são exigidos em 
exames de vestibular, concursos, etc., dos alunos em fase de conclusão do Ensino Médio, bem como dos professores participantes conhecimentos específicos em LÊ, de modo a possibilitar a ampliação do campo de atuação profissional dos participantes.

Os excertos grifados nos dois recortes acima revelam que, para os alunos-professores, o acesso à informação em LE nos textos pertencentes ao gênero biografia e notícia está fortemente ligado à circulação desses gêneros na esfera cotidiana, o que vincula a compreensão do aluno ao texto escrito em LE ao seu conhecimento prévio sobre o gênero.

A relação entre conhecimento de mundo e compreensão escrita pode ser observada nas declarativas Uma vez que homem e história estão relacionados... podemos incitar nos alunos a curiosidade quando se relata acontecimentos de uma pessoa famosa (Recorte 1) e o gênero Notícia foi escolbido por sua acessibilidade (Recorte 2). Essas declarativas revelam a compreensão dos alunos-professores sobre o nível de conhecimento que os PCNs de LE classificam como conhecimento de mundo e a percepção de que este deve ser acessado e valorizado no processo de compreensão escrita.

Embora ambas as justificativas revelem a preocupação com o acesso ao texto escrito em LE via conhecimento prévio e conhecimento do gênero, a relação que se estabelece com o conhecimento de mundo em cada uma delas parece ser de natureza consideravelmente distinta. Enquanto a facilidade de acesso às informações sobre pessoas famosas, ou seja, o conhecimento prévio que os alunos têm sobre celebridades facilita a busca de informações nas biografias e torna a leitura desse gênero mais prazerosa, o acesso à notícia é visto como uma forma de transcender o conhecimento de mundo do aluno na medida em que considera a possivel necessidade dos alunos de adquirir conbecimento de fatos em Lingua Inglesa (Recorte 2) de forma a desenvolver aptidões requeridas no vestibular e ampliar o campo de atuação profissional dos participantes.

Além da percepção em relação ao papel do conhecimento de mundo no processo de compreensão escrita, os objetivos estabelecidos para cada seqüência didática revelam a compreensão dos alunos-professores sobre os outros níveis de conhecimento que, 
segundo os PCNs de LE, são mobilizados para construção de significados e engajamento discursivo do aprendiz na LE - o conhecimento sistémico e o conhecimento da organização textual.

O quadro a seguir relaciona esses três níveis de conhecimento com os objetivos estabelecidos nos planos de curso referentes a cada uma das seqüências didáticas.

\begin{tabular}{|c|c|c|c|}
\hline & $\begin{array}{l}\text { Conhecimento de } \\
\text { Mundo }\end{array}$ & $\begin{array}{l}\text { Conhecimento } \\
\text { sistêmico }\end{array}$ & $\begin{array}{l}\text { Conhecimento da } \\
\text { organização textual }\end{array}$ \\
\hline \multirow[t]{3}{*}{ SD - Fábula } & $\begin{array}{l}\text { Utilizando-se do } \\
\text { conhecimento (de } \\
\text { mundo, sistêmico, } \\
\text { textual) já adquirido } \\
\text { pelo aluno bem } \\
\text { como das } \\
\text { semelhanças entre } \\
\text { LE e LM. }\end{array}$ & & $\begin{array}{l}\text { Levar o aluno a } \\
\text { compreender as } \\
\text { características básicas } \\
\text { do gênero fábula e } \\
\text { refletir sobre essas } \\
\text { características a partir } \\
\text { das fábulas The Hare } \\
\text { and lhe Tortoise e The } \\
\text { Camel.. }\end{array}$ \\
\hline & \multirow{2}{*}{\multicolumn{2}{|c|}{$\begin{array}{l}\text { Utilizar-se de palavras cognatas para a } \\
\text { compreensão dos textos }\end{array}$}} & $\begin{array}{l}\text { Reconhecer } \\
\text { características } \\
\text { fundamentais da } \\
\text { fábula }\end{array}$ \\
\hline & & & $\begin{array}{l}\text { Estabelecer } \\
\text { diferenças } \\
\text { comparando os } \\
\text { textos abordados. }\end{array}$ \\
\hline SD - Biografia & $\begin{array}{l}\text { Ativar o } \\
\text { conhecimento prévio } \\
\text { do aluno sobre o } \\
\text { gênero biográfico, } \\
\text { estimulando-o a } \\
\text { compartilhá-lo com } \\
\text { seus colegas de } \\
\text { forma natural e } \\
\text { descontraída }\end{array}$ & \begin{tabular}{|l|} 
Ampliar o \\
conhecimento de \\
inglês do aluno, \\
possibilitando o \\
conhecimento \\
sistemático de \\
tempos verbais \\
(Present Simple, Past \\
Simple e Present Perfect) \\
e preposições (de \\
tempo e de lugar) \\
mais frequentes nas \\
biografias.
\end{tabular} & $\begin{array}{l}\text { Oferecer mecanismos } \\
\text { para que o aluno } \\
\text { desenvolva suas } \\
\text { habilidades em leitura } \\
\text { através de análise de } \\
\text { textos biográficos que } \\
\text { darão suporte para a } \\
\text { elaboração de uma } \\
\text { biografia construída } \\
\text { por meio do } \\
\text { conhecimento } \\
\text { adquirido no decorrer } \\
\text { do curso. }\end{array}$ \\
\hline \multirow[t]{3}{*}{ SD - Notícia } & \multicolumn{3}{|c|}{$\begin{array}{l}\text { Desenvolver a habilidade de leitura em Língua Inglesa a partir de } \\
\text { Notícias, de modo a inter-relacionar os três níveis de conhecimento } \\
\text { (de mundo, sistêmico, organização textual) }\end{array}$} \\
\hline & & & $\begin{array}{l}\text { Possibilitar o acesso } \\
\text { a informações em } \\
\text { LE através de } \\
\text { notícias }\end{array}$ \\
\hline & & & $\begin{array}{l}\text { Capacitar o aluno em } \\
\text { leitura e interpretação } \\
\text { do gênero notícia, } \\
\text { tendo em vista a } \\
\text { necessidade do } \\
\text { vestibular }\end{array}$ \\
\hline
\end{tabular}


Verifica-se, no quadro, uma preocupação significativa dos alunos-professores de construir por meio da seqüência didática o conhecimento da organização textual do gênero selecionado. Isso revela a influência do modelo didático calcado em teorias de gêneros previamente estabelecido e discutido e o diálogo estabelecido pelos alunos-professores entre esse modelo e as diretrizes dos PCNs de LE. $^{2}$

Nesse diálogo, o conhecimento da organização textual implica a construção do conhecimento da estrutura do gênero que pode ser constituído a partir da compreensão e do reconhecimento das características básicas do gênero fábula e reflexão sobre essas características; da comparação entre diferentes fábulas; do desenvolvimento das habilidades em leitura através da análise de textos biográficos; do acesso a informações em LE através de noticias e da interpretação do gênero notícia.

Retomando aqui a relação entre os três níveis de conhecimento preconizados pelos PCNs de LE e as três dimensões essenciais do gênero definidas por Scheneuwly \& Dolz (2004), observa-se que os objetivos estabelecidos pelos alunos-professores para cada seqüência didática contemplam a primeira e segunda dimensões.

A primeira dimensão - "os conteúdos que são (ou se tornam) dizíveis através do gênero" - é contemplada tanto nos objetivos relacionados ao conhecimento de mundo quanto naqueles associados ao conhecimento da organização textual, visto que a utilização do conhecimento de mundo e a análise das características específicas do gênero buscam viabilizar o processo de compreensão e interpretação dos textos em LE.

Quanto à segunda dimensão - "a estrutura (comunicativa) particular dos textos pertencentes ao gênero" - observa-se, conforme mencionado anteriormente, a preocupação dos alunos-professores de descrever as características dos gêneros e o diálogo estabelecido entre o nível do conhecimento da organização textual e o conhecimento de aspectos do gênero selecionado.

Por fim, a terceira dimensão - "as configurações específicas das unidades de linguagem, que são sobretudo traços da posição

\footnotetext{
${ }^{2}$ É importante ressaltar que o conhecimento da organização textual nos PCNs de LE (BRASIL, 1998a) não estabelece relações com a concepção de gêneros do discurso.
} 
enunciativa do enunciador, e os conjuntos particulares de seqüências textuais e de tipos discursivos que formam sua estrutura" -, que pode ser relacionada com o conhecimento sistémico, só é contemplada em um dos objetivos delimitados para a seqüência didática referente ao gênero biografia, que faz referência explícita à construção do conhecimento sobre tempos verbais e preposições nesse gênero. No entanto, não se especifica a intenção de se estabelecer relações entre esse conhecimento sistémico e a posição enunciativa do enunciador de forma a relacionar as ideologias enunciadas no texto com a(s) esfera(s) de circulação do gênero e com o contexto sócio-histórico mais amplo.

\section{Considerações finais}

Busquei, nesse artigo, descrever o projeto Seqüencias didáticas para o ensino de leitura em língua inglesa: elaboração e aplicaşão desenvolvido nas minhas aulas de Prática de Ensino da Universidade Federal do Acre e, a partir da análise de recortes dos planos de curso dos alunosprofessores do $8^{\circ}$ período, suscitar reflexões sobre o processo de formação desencadeado no projeto.

Embora o projeto ainda esteja em desenvolvimento e uma descrição mais detalhada dos resultados e impactos demande uma análise que inter-relacione mais profundamente as seqüências didáticas com o processo de ensino-aprendizagem e de formação observados, é possível propor que o projeto vem contribuindo para:

- realizar ações na área de Formação de Professores de LE que conjuminem com o novo Projeto Pedagógico do Curso de Letras da UFAC, com as novas Diretrizes Curriculares para Formação de Professores e com as pesquisas atuais na área de Educação e Linguística Aplicada;

- buscar caminhos que façam com que a Prática de Ensino de Língua Inglesa no Curso de Letras/Inglês da UFAC constitua um espaço que permita ao aluno vivenciar de fato a prática pedagógica, intervindo de forma colaborativa e transformadora na escola onde o estágio/observação são realizados;

- levar o aluno a compreender, analisar e refletir criticamente sobre as relações entre os construtos teórico-metodológicos estudados no decorrer do curso e situações concretas de 
ensino-aprendizagem e LE;

- refletir criticamente sobre minha intervenção e contribuição na formação pré-serviço dos alunos.

A discussão realizada reforça a concepção dos PCNs de LM (Brasil, SEF/MEC, 1998) e de pesquisadores como Dolz \& Schneuwly (2004) Cristóvão (2001 e 2002), Rojo (2001 e 2005), Szundy (2004 e 2005), entre outros, de que a utilização de gêneros como instrumentos de ensino-aprendizagem pode criar zonas potenciais e revolucionárias para a constituição da compreensão e produção escrita, permitindo que a construção do conhecimento ocorra de fato em espiral, passando por um mesmo ponto (ou gênero) a cada nova revolução.

\section{Referências}

BAKHTIN, M. V. (VOLOSHINOV). Marxismo e Filosofia da Linguagem. Trad. Michel Lahud e Yara Frateschi Vieira. São Paulo: Hucitec, [1929] 1999.

Questões de Literatura e de Estética: a teoria do romance. São Paulo: Editora da UNESP, [1975] 1998.

BRASIL. SEF/MEC. Parâmetros Curriculares Nacionais - $3^{\circ}$ e $4^{\circ}$ ciclos do Ensino Fundamental - Língua Estrangeira. Brasília, DF: SEF/MEC, 1998a.

SEF/MEC. Parâmetros Curriculares Nacionais - $3^{\circ}$ e $4^{\circ}$ ciclos do Ensino Fundamental - Língua Portuguesa. Brasília, DF: SEF/MEC, 1998b.

CELANI, M. A. A. (Org.) Professores e formadores em mudança: relato de um processo de reflexão e transformação da prática docente. Campinas: Mercado de Letras, 2002.

CRISTOVÃO, V. L. L. O gênero quarta-capa no ensino de inglês. In: DIONÍSIO, A. P.; MACHADO, A. R.; BEZERRA, M. A. (Org.) Gêneros Textuais e ensino. Rio de Janeiro: Lucerna, 2002. p. 95-106. 
Gêneros e ensino de leitura em LE: os modelos didáticos de gêneros na construção e avaliação de material didático. 2001. Tese (Doutorado em Lingüística Aplicada e Estudos da Linguagem) Pontifícia Universidade Católica, São Paulo.

; NASCIMENTO, E. L. Gêneros textuais e ensino: contribuições do interacionismo sócio-discursivo. In: KARWOSKI, A. M.; GAYDCSKA, B.; BRITO, K. S. (Org.) Gêneros Textuais: reflexões e ensino. União da Vitória: Kaygangue, 2005. p. 35-60.

DOLZ. J.; SCHNEUWLY, B. Gêneros e progressão em expressão oral e escrita - elementos para reflexões sobre uma experiência suíça (francófona). In: ROJO, R.; CORDEIRO, G. S. (Orgs. e Trads.) Gêneros orais e escritos na escola. São Paulo: Mercado de Letras, 2004. p. 41-70.

MARCUSCHI, L. A. Gêneros textuais: configuração, dinamicidade e circulação. In: KARWOSKI, A. M.; GAYDCSKA, B.; BRITO, K. S. (Org.) Gêneros Textuais: reflexões e ensino. União da Vitória: Kaygangue, 2005. p. 17-33.

PINTO, A. P. Gêneros discursivos e ensino de língua inglesa. In: DIONÍSIO, A. P.; MACHADO, A. R.; BEZERRA, M. A. (Org.) Gêneros Textuais e Ensino. Rio de Janeiro: Editora Lucerna, 2002, p. 47-57.

RAMOS, R. C. G. Gêneros textuais: uma proposta de aplicação em cursos de inglês para fins específicos. The ESPecialist, v. 25, n. 2, p. $107-$ 129, 2004.

ROJO, R. H. R. Modos de transposição dos PCNs às práticas de sala de aula: progressão curricular e projetos. In: ROJO, R. H. R. (Org.) $A$ prática da linguagem em sala de aula: praticando os PCNs. São Paulo: Mercado de Letras/EDUC, 2001.

Gêneros do discurso e gêneros textuais: questões teóricas e aplicadas. In: MEURER, A. B.; MOTTA-ROTH, D. (Org.). Gêneros teorias, métodos, debates. São Paulo: Parábola, 2005. p. 184-207. 
SZUNDY, P. T. C. Gêneros do discurso no processo de ensinoaprendizagem de LE: a construção do conhecimento por meio do discurso internamente persuasivo. The ESPecialist, v. 25, n. 2, p. 153$175,2004$.

- A construção do conbecimento no jogo e sobre o jogo: ensinoaprendizagem de LE e formação reflexiva. 2005. Tese (Doutorado em Lingüística Aplicada e Estudos da Linguagem) - Pontifícia Universidade Catpolica, São Paulo.

VYGOTSKY, L. S. Pensamento e Linguagem. Trad. Jefferson Luiz Camargo. São Paulo: Martins Fontes, [1934] 1998. 